\title{
Hospitalized older adults: functional trajectory in a Portuguese hospital
}

A pessoa idosa hospitalizada: trajetória funcional em hospital português El anciano hospitalizado: trayectoria funcional en un hospital portugués

João Paulo de Almeida Tavares*iD; Joana Grácio**; Lisa Nunes***

\begin{abstract}
Background: The functional trajectory (FT) of hospitalized older adults (HOA) is an important and underestimated prognostic concept.

Objective: To analyze the FT of HOA between baseline and 3-month follow-up.

Methodology: Prospective cohort study with $101 \mathrm{HOA}$ admitted to departments of internal medicine. Functionality was assessed using the Katz Index at 3 moments: baseline, discharge, and follow-up. Functional decline (FD) was defined as the loss of at least one point on the Katz Index, compared to baseline score.

Results: A FD of 54.5\% occurred between baseline and hospital discharge. In the follow-up, $41.6 \%$ of the older adults did not recover baseline functional status. Four main trajectories were identified: improvement (7.53\%), stability $(30.11 \%)$, recovery $(25.81 \%)$, and decline $(36.55 \%)$.

Conclusion: FD is very significant. Functional recovery occurs mainly after hospital discharge. Hospitals and practitioners should adopt care interventions or models focused on maintaining or restoring functionality during hospitalization and enhancing post-discharge rehabilitation.
\end{abstract}

Keywords: aged; functional decline; hospitalization

\section{Resumo}

Enquadramento: A trajetória funcional (TF) das pessoas idosas hospitalizadas (PIH) é um conceito de prognóstico importante e subestimado.

Objetivo: Analisar a TF das PIH entre a baseline e o follow-up de 3 meses.

Metodologia: Estudo de coorte prospetivo com $101 \mathrm{PIH}$ nos serviços de medicina interna. A funcionalidade foi avaliada através do Índice de Katz em 3 momentos: na $b a$ seline, na alta e no follow-up. O declínio funcional (DF) foi definido como a reduçáo em pelo menos um ponto na pontuação do Katz, em comparação com a baseline.

Resultados: Identificou-se um DF de 54,5\% entre a baseline e a alta. No follow-up, 41,6\% das PIH não recuperaram o status funcional da baseline. Identificaram-se 4 trajetórias principais: melhoria $(7,53 \%)$, estabilidade $(30,11 \%)$, recuperação $(25,81 \%)$ e declínio (36,55\%).

Conclusáo: O DF é muito significativo. A recuperaçáo funcional ocorre essencialmente após a alta hospitalar. Os hospitais e os profissionais devem adotar intervençóes ou modelos de cuidado focados na manutençáo ou recuperaçáo da funcionalidade durante a hospitalização e intensificar a reabilitação pós-alta.

Palavras-chave: idoso; declínio funcional; hospitalização

*Ph.D., MSc., RN, Personalized Healthcare Unit - Soure, Alfarelos Unit, 3130-001, Alfarelos, Portugal [enfjoaotavares@esenf.pt]. (10 https://orcid.org/0000-0003-3027-7978. Contribution to the article: literature search, study conception and design, data collection, data analysis and treatment, statistical analysis, and article writing. Address for correspondence: Rua António José de Almeida, Lote $12,6^{\circ}$ Esq. 3000-046, Coimbra, Portugal.

**MSc., RN, Coimbra Hospital and University Center, 3000-075, Coimbra, Portugal [joana.c. gracio@hotmail.com].Contribution to the article: literature search, study conception and design, data collection, data analysis and treatment, statistical analysis, and article writing. ***MSc., RN, Coimbra Hospital and University Center, 3000-075, Coimbra, Portugal llisa veiga@hotmail.com].Contribution to the article: literature search, study conception and design, data collection, data analysis and treatment, statistical analysis, and article writing.

\section{Resumen}

Marco contextual: La trayectoria funcional (TF) de las personas ancianas hospitalizadas (PAH) es un concepto de pronóstico importante y subestimado.

Objetivo: Analizar la TF de las PAH entre el punto de referencia y el seguimiento de 3 meses.

Metodología: Estudio de cohorte prospectivo con 101 $\mathrm{PAH}$ en los servicios de medicina interna. La funcionalidad se evaluó a través del Índice de Katz en 3 momentos: en el punto de referencia, en el alta y el seguimiento. El declive funcional (DF) se definió como la reducción en al menos un punto en la puntuación de Katz, en comparación con el punto de referencia.

Resultados: Se identificó un DF del 54,5 \% entre el punto de referencia y el alta. En el seguimiento, el 41,6\% de las $\mathrm{PAH}$ no recuperaron el estatus funcional del punto de referencia. Se identificaron 4 trayectorias principales: mejora $(7,53 \%)$, estabilidad $(30,11 \%)$, recuperación $(25,81 \%)$ y declive $(36,55 \%)$.

Conclusión: El DF es muy significativo. La recuperación funcional ocurre esencialmente después del alta hospitalaria. Los hospitales y los profesionales deben adoptar intervenciones o modelos de cuidado enfocados en el mantenimiento o la recuperación de la funcionalidad durante la hospitalización, así como intensificar la rehabilitación después del alta.

Palabras clave: anciano; declive funcional; hospitalización

Recebido para publicação: 07.05 .18

Aceite para publicação: 31.07 .18

Série IV - n. ${ }^{0} 18$ - JUL./AGO./SET. 2018 


\section{Introduction}

Population aging in Portugal has increased in recent decades, placing Portugal as the fifth most aged country in the world (United Nations, 2015). This situation will have a significant impact on the demand for health care, especially for hospital admissions which have increased steadily (Conroy, Stevens, Parker, \& Gladman, 2011). The concern about the hospitalization of older adults (OA) is associated with: high rates; long hospital stays; associated costs; and the vulnerability of this age group to adverse events. Among these events are the changes in mental status (e.g., delirium, cognitive decline, depression), undernutrition and dehydration, continence, changes in skin integrity, sensory deprivation, and functional decline (FD; Admi, Shadmi, Baruch, \& Zisberg, 2015). FD is one of the main consequences of hospitalization and is associated with decreased quality of life and higher mortality rates during and after hospital stay (Palese et al., 2016). FD can occur before, during, and after hospitalization due to intrinsic and extrinsic factors (Tavares, Grácio, \& Nunes, 2017a). In Portugal, a study found that $76.2 \%$ of hospitalized older people were at risk for FD during and after hospitalization (Tavares et al., 2017a). Despite the high risk and significant decline rates, the authors of this study are not aware of any studies on the functional trajectory (FT) of hospitalized older people between baseline ( 2 weeks before hospitalization) and 3 months after discharge. FT is an important prognosis concept which is underestimated by health organizations and/or professionals. Therefore, the purpose of this study was to analyze the FT of hospitalized older people between baseline, discharge, and 3-month follow-up.

\section{Background}

Systematic reviews show that FD is the most common unfavorable health outcome resulting from hospital stays, with long-term consequences for $\mathrm{OA}$, informal caregivers, and the health system (Covinsky, Pierluissi, \& Story, 2011). A systematic review demonstrated that $30 \%$ to $60 \%$ of hospitalized older people have FD (Hoogerduijn, Schuurmans, Duijnstee, De Rooij, \& Grypdonck, 2007). Covinsky et al.
(2011) reported that approximately $30 \%$ of OA aged 70 years or more and $50 \%$ of older people aged 85 years or more will be discharged from the hospital with a new disability. More recent studies reinforce these results, arguing that OA often suffer from FD during and after hospitalization (Boltz, Lee, Chippendale, \& Trotta, 2018; D’Onofrio, Bula, Rubli, Butrogno, \& Morin, 2018; Palese et al., 2016).

FD is associated with several risk factors, namely: personal factors (e.g.., age, functional and cognitive status prior to hospitalization; Covinsky et al., 2011); psychological factors (e.g., depression); social factors (e.g., informal support network); hospitalization-related factors (e.g., limited mobility and bed rest, delirium, polypharmacy, use of psychotropic drugs, direct and indirect restraint, malnutrition, and use of medical devices, such as urinary catheters; Hoogerduijn et al., 2007; Palese et al., 2016), and environmental and political factors that do not promote independence (Tavares, Grácio, \& Nunes, 2017b).

Several studies have been conducted to explore the effect of FD at different moments after hospital discharge, namely at 3, 6, 9, and 12 months (Covinsky et al., 2011; D'Onofrio et al., 2018; Palese et al., 2016; Zisberg, Shadmi, Gur-Yaish, Tonkikh, \& Sinoff, 2015). After hospital discharge, patients can have different functional trajectories. Some of them continue on the downward path of decline, others recover baseline functional status (1 to 3 months after discharge), and others maintain the same functional status (Huang, Chang, Liu, Lin, \& Chen, 2013; Medina-Mirapeix et al., 2016; Wakefield \& Holman, 2007). Post-discharge FD can extend to one year, and the lack of recovery of baseline functional status is associated with the risk of institutionalization, long-term disability, and death (up to 3 years; Boyd et al., 2008). It has been demonstrated that FD at pre-admission and during hospitalization have an impact on patients' functional outcome 3 months after hospital discharge (Covinsky et al., 2011).

\section{Research question}

What is the FT of hospitalized older adults between baseline, discharge, and 3 months post-discharge (follow-up)? 


\section{Methodology}

\section{Type of study}

A prospective cohort study was conducted in four departments of internal medicine (two inpatient units for men and two for women) of a central university hospital in the center region of Portugal. FD was defined as the loss of at least one point on the Katz Index, between functional status assessments during the data collection period. FD was divided into without decline (maintenance of the total score between assessments) and with decline (loss of at least one point between assessments). The t0 moment corresponds to the subtraction of baseline and discharge scores (which indicates the impact of the disease and hospitalization on changes in scores of basic activities of daily living - ADL); $\mathrm{t} 1$ corresponds to the subtraction of discharge and follow-up scores; and 2 corresponds to the subtraction of baseline and follow-up scores.

\section{Population and sample}

The target population is composed of older adults aged $\geq 70$ years who had been admitted to departments of internal medicine. The sample was calculated using the G-power software (effect size of 0.5 and power $(\beta)$ of 0.8 ), in a total of 101 participants. This was a nonprobability, accidental sample obtained by consecutive sampling. The following inclusion criteria were applied: ability to understand and interpret the survey questions (an informal caregiver may be asked to answer if the patient is unable to answer) and agreeing to participate in the study. The exclusion criteria were as follows: patients transferred from intensive care units, with neurodegenerative or terminal illness, totally dependent at baseline (maximum score in the Katz Index), and hospitalization of less than 48 hours. A total of 117 patients were included, of whom 16 were excluded for the following reasons: death $(n=4)$, transfer to another unit $(n=$ 4 ), lack of baseline assessment $(n=1)$, and hospitalization of more than 48 hours in the short-term inpatient unit $(n=1)$. The final sample was composed of 101 patients.

\section{Variables and instruments}

In this study, a set of variables were assessed in different moments ( $\mathrm{t} 0, \mathrm{t} 1$, and $\mathrm{t} 2)$. At admission, the following variables were assessed: demographic characteristics (e.g., age, gender, education level, marital status, residence), clinical characteristics (e.g., diagnosis on admission, clinical history, Charlson Comorbidity Index), geriatric conditions (e.g., delirium, cognitive status, weight loss, fall risk, risk of pressure ulcers, mood), and functionality. At discharge, the following variables were assessed: length of hospital stay, fall during hospitalization, functionality, post-discharge destination, and support at home. In the follow-up, the variables were functionality, place of residence, support at home, the visit to the emergency department, hospital readmission, and death.

The Katz Index was used to assess functionality. It includes 6 items: bathing, dressing, transferring, toileting, continence, and feeding (Duke, Gruner, Clara, Ermida, \& Veríssimo, n.d.). Each activity is scored from 0 (dependence) to 1 (independence). The final score results from the sum of each item score, corresponding to 5 levels: independence (6 points); mild dependence (5 points); moderate dependence ( 4 to 3 points); severe dependence (2 to 1 points); and total dependence (0 points).

\section{Data collection}

This study was approved by the hospital's Ethics Committee, with opinion no. CHUC-06514. Data were collected between 1 May and 7 October, 2016: baseline, admission, and discharge data were collected from 1 May to 30 June, and follow-up data from 5 August to 7 October. Patients who had been hospitalized in the past 48 hours were identified electronically. The researchers invited patients who met the eligibility criteria to participate in the study. In the first 48 hours after signing the informed consent form, the data collection started.

The researchers completed the questionnaire in three moments: at baseline, to obtain data for demographic, clinical, and functional characterization, and at discharge and follow-up, to obtain data on the functional status.

Participants were contacted by phone to obtain the Katz Index scores at discharge (when it was not possible to assess it during hospitalization) and follow-up. To obtain information on functionality, the patient was contacted (either during the interview or by phone) or, whenever the patient was 
unable to answer, formal or informal caregivers were contacted to provide this information.

\section{Data analysis}

Data were analyzed using IBM SPSS Statistics software, version 23. Data on people who died during hospitalization or the follow-up period were excluded from analysis. In descriptive statistics, measures of central tendency such as the mean and the median, and measures of dispersion such as the standard deviation were used for continuous variables, whereas relative frequencies (percentages) were used for nominal variables. In the comparative analysis between the Katz Index scores, the Student's $t$-test was used (if the normality assumption was not verified, the Mann-Whitney $U$ test was used). A $p$-value of $<0.05$ was considered statistically significant.

\section{Results}

\section{Sample description}

Half of the sample was composed of female patients $(53.3 \%)$, with a mean age of $82.47 \pm$ 6.57 years, mostly widow (49\%) and married patients (46\%). More than half of them had a low education level ( $0-2$ years; $57.4 \%)$. They lived in their own homes $(42.4 \%$ with their spouse) or with relatives (83.2\%). Almost half of the diagnoses were infections (42.6\%), followed by cardiovascular diseases $(17.8 \%)$ and hydroelectrolytic imbalance $(12.9 \%)$. The majority of patients were polymedicated $(75.2 \%$; mean of $7.42 \pm 3.89$ drugs), had a median of $6(4-7)$ in the Charlson Comorbidity Index (0-8), and an Estimated Relative Risk of Mortality $(0-19.37)$ of $9.23(4.4-13.4)$.

More than two thirds $(71.3 \%)$ of the sample reported weight loss, $48 \%$ were at high risk of falling, and $32.3 \%$ were at high risk of developing pressure ulcers. More than half (58\%) of hospitalized older adults had no cognitive impairment but reported feeling often sad or depressed (68\%).

\section{Functional trajectory}

In this sample, $55.4 \%$ of participants were independent at baseline, which decreased at discharge $(24.7 \%)$. Thus, more than half of the patients $(54.5 \%)$ had FD in t0 (in one, two or three ADL: $23.8 \%, 12.9 \%$, and 9.9\%, respectively). Decline was higher in the following ADL: bathing (39.9\% vs $66.9 \%)$ and dressing $(21.8 \%$ vs $50.5 \%)$. Feeding was the ADL in which people remained more independent. At follow-up, patients improved their functional status, even though it does not reflect baseline (Table 1).

Table 1

Analysis of Katz Index categories

\begin{tabular}{lccc}
\hline Categories (\%) & Baseline $(N=101)$ & $\begin{array}{l}\text { Discharge } \\
(N=101)\end{array}$ & Follow-up $(N=93)$ \\
\hline Total dependence & - & $5(5)$ & $5(5.4)$ \\
Severe dependence & $12(11.9)$ & $22(21.8)$ & $15(16.1)$ \\
Moderate dependence & $14(13.9)$ & $25(24.8)$ & $13(14)$ \\
Mild dependence & $19(18.8)$ & $18(17.8)$ & $16(17.2)$ \\
Independence & $56(55.4)$ & $31(30.7)$ & $44(47.3)$ \\
\hline
\end{tabular}

Patients with greater functional potential (independence, mild dependence, and moderate dependence) are those whose decline in ADL was higher between baseline and discharge. Only patients with moderate dependence at baseline improved their Katz mean score (1.67 to 1.75 ), although not significantly. Patients with total dependence at discharge had Katz mean scores of 2.8 at baseline. Patients who were independent or moderately independent had more functional gains between discharge and follow-up. Despite this functional improvement, no mean baseline Katz Index scores were recovered in any of the categories (Figure 1). 


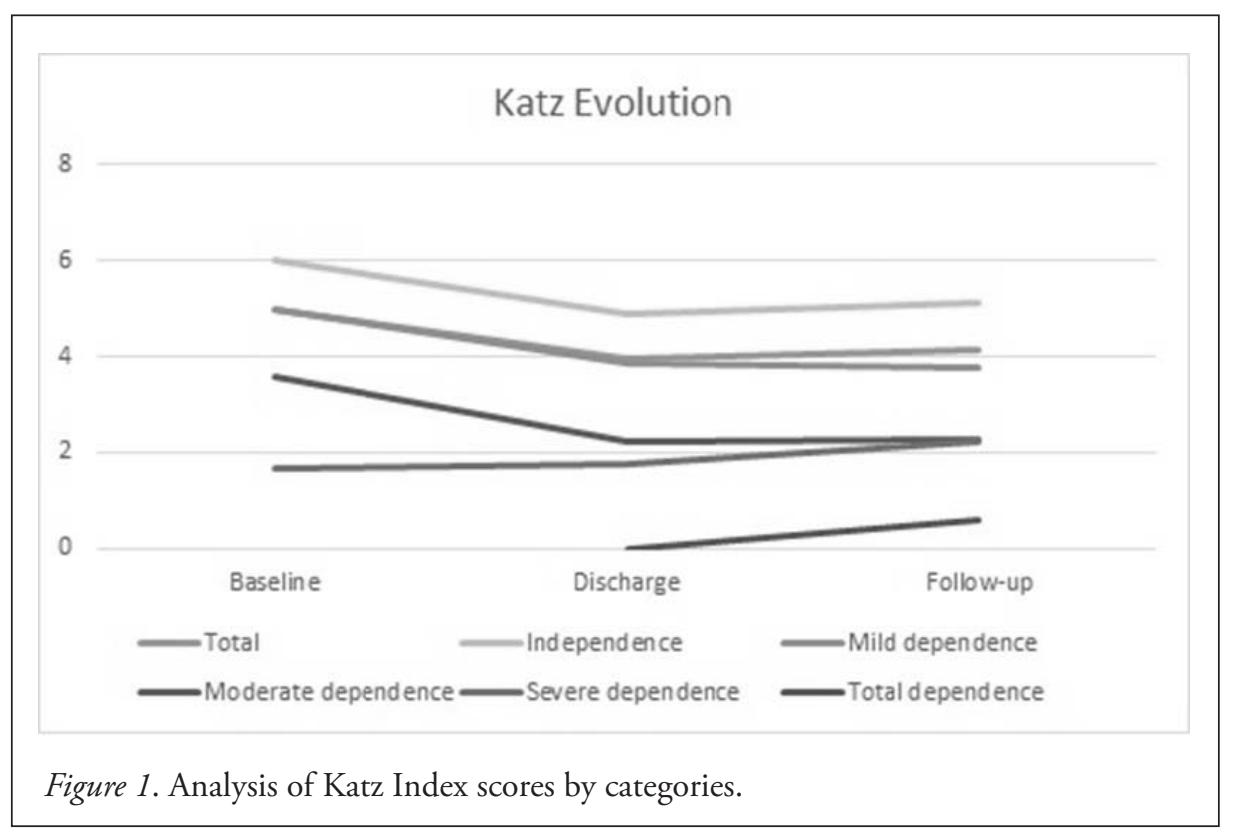

By dividing the sample between patients with decline and those without decline during the three moments, patients with decline at baseline had a mean Katz Index score of 4.28, which is lower than that of patients without decline. At discharge, patients with decline had lower mean scores than patients without decline (2.8 versus 5.3 ). At follow-up, the mean number of patients with decline was higher than the mean number of patients with decline at discharge. However, it was lower than the mean Katz Index score of the group without decline (3.29 versus 5.1 ).

Figure 2 shows the trajectories based on the results obtained in the follow-up. Four main trajectories were identified at baseline: improvement $(n=7)$, stability $(n=28)$, recovery $(n=24)$, and decline $(n=34)$.

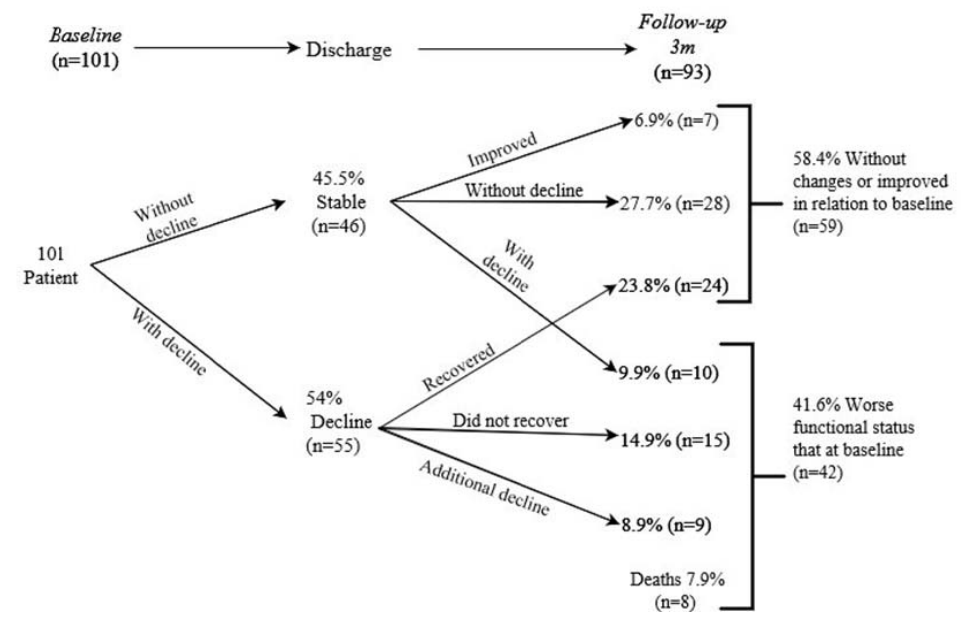

Figure 2. Functional trajectory between baseline, discharge, and follow-up. 
In t0, functional decline was statistically significant for Katz scores at baseline (4.96) and discharge (3.94); $\mathrm{t}(100)=6.76 ; p<0.01$. In $\mathrm{t} 0,6.9 \%$ of patients had improved in relation to baseline. The analysis of $\mathrm{t} 1$ showed no statistically significant differences between the Katz score at discharge (4.12) and at follow-up (4.43); $\mathrm{t}(92)=-1.84 ; p=0.07$. From baseline (5.01) to follow-up (4.42), a statistically significant functional decline $(\mathrm{t}(92)=$ 3.39; $p<0.01$ ) occurred.

On the one hand, a very significant number of patients regained functionality after discharge, despite the decline during the hospitalization period. However, this group never recovered their baseline scores. On the other hand, a group of OA with functional decline trajectories in t0 kept the same trajectory in $t 1$. The group of patients who improved in t0 showed a positive correlation with the group who showed functional decline in $\mathrm{t} 1(2.5 ; n=4)$. These data suggest that the functional gains during hospitalization may not continue after that period. Moreover, these gains were observed on patients with severe dependence.

Of the analyzed variables, it should be noted that people with cognitive impairment were more dependent (lower Katz Index scores) at baseline, discharge, and follow-up ( $p \leq 0.01)$. Patients who reported feeling sad or depressed also had higher dependence scores $(p \leq 0.01)$.

\section{Discussion}

The results show that more than half of older adults admitted to the departments of internal medicine showed FD during hospitalization. These data are similar to those found in the same departments in Spain (53.5\%; Astiz et al., 2008), although they are higher than those found in other studies (Covinsky et al., 2011; Huang et al., 2013; Palese et al., 2016; Zisberg et al., 2015). It should be emphasized that older adults hospitalized in medical departments tend to be more vulnerable, frailer, older (inclusion criterion: aged more than 70 years), and have multiple comorbidities (51.5\%). Although most of the conditions leading to hospitalization have significantly improved at discharge, the functional trajectory followed a downward spiral (Covinsky et al., 2011). These results reinforce what Covinsky et al. (2011) defined as hospitalization-associated disability. These authors reported that $50 \%$ of $\mathrm{OA}$ aged 85 years or more will have at least one new ADL disability at discharge.

The inconsistency between the improvement in the clinical and functional trajectories (Zisberg et al., 2015) reinforces the idea that the recovery of lost ADL during the disease process is as important for older people as the treatment itself. During and after hospitalization, patients may experience different changes in functional trajectories, staying about the same or gradually improving or declining (Huang et al., 2013; Palese et al., 2016; Sleiman et al., 2009; Wakefield \& Holman, 2007), as in this study. Data revealed that $58.4 \%$ of patients had maintained or improved their functional trajectory at follow-up and that $41.6 \%$ had worse functional status at follow-up than at baseline. However, at discharge, $54.5 \%$ had worsened during hospitalization, which confirms that functional status is mainly recovered after hospital discharge.

Studies reveal an interaction between the different assessment periods and those obtained by patients with or without FD (Zisberg et al., 2015). This study showed that patients with FD scored higher on the Katz Index, which is consistent with the results of other studies (D'Onofrio et al., 2018; Huang et al., 2013). In this group, although the mean Katz Index scores increased from discharge to follow-up, baseline functional levels were not recovered. Given this finding, it is important to reconsider the delivery of care to more independent hospitalized OA with a view to improving functionality and offering rehabilitation care as early as possible.

In this study, 7 of the 8 patients who died after discharge had declined during hospitalization, being more likely to die within 3 months after discharge (Wakefield \& Holman, 2007). However, the number of cases limited the statistical analysis.

Previous studies have shown that patients who declined after discharge had maintained their functional status during hospitalization but deteriorated 3 months later (Sleiman et al., 2009). In this study, 9.9\% of patients 
remained stable during hospitalization, but declined in the following 3 months. Patients without FD at discharge (34.6\%) either improved or maintained their functional status during the study period, which is a similar finding to that found in other studies (Covinsky et al., 2011; Huang et al., 2013). In this study, $23.8 \%$ of patients who declined during hospitalization regained baseline functional status. Future studies should explore the factors facilitating the recovery of baseline functional status after hospital discharge.

The analysis of the functional trajectories in this study shows that the majority of older adults had more health needs after hospitalization than at baseline. Consequently, the demands on the caregivers will also increase significantly. These results have major implications for the health and social systems both during and after hospitalization. The prevention of functional decline in older adults can be the key to improving health outcomes for patients, families, caregivers, and organizations. Therefore, there is an urgent need to rethink the professionals' physical and work environment, as well as the health care policies and practices so that hospitals can promote functionality rather than dependence and decline.

\section{Study limitations and future perspectives}

This study has some limitations. The first limitation is that the functional trajectory comprised 3 moments (baseline, discharge and follow-up) but did not include the moment of admission, which may have limited the understanding of functional trajectory. Future studies should consider the assessment of functionality at admission in order to help clarifying the impact of the disease on functional trajectory. Although the impact of the acute disease can be significant, functional trajectory may occur independently (Boyd et al., 2008) and hospitalization can play a very important role (Covinsky et al., 2011). The second limitation relates to the fact that, although patients have been assessed in three moments, it is likely that other changes in functionality have occurred between observation moments, particularly from discharge to follow-up. The third limitation is associated with the instrument used in this study.
The Katz Index, with a dichotomous scoring (dependence or independence) was chosen because it is the most widely used index in the studies on functional decline and the one used in the hospital where the study took place. However, the use of its modified version (which includes four levels of support) or the Barthel Index would enable a more in-depth understanding of the type of dependence among OA. The fourth limitation is the 3-month follow-up period, which can be considered too short to assess functional recovery. Thus, these results may underestimate recovery rates. As functional trajectory significantly improves after discharge, future studies should consider assessing functional trajectory at 6 months and 12 months after discharge. Finally, this study was conducted in a central and university hospital and in an internal medicine department, thus the generalization of results is limited. Similar studies should be conducted in different types of hospitals and include other departments.

\section{Conclusion}

More than half of older adults showed FD during hospitalization. FD was more evident among patients who were more independent at baseline. Functional recovery occurs mainly after discharge, although a significant number of patients $(n=34)$ do not regain their previous functional status, resulting in significant consequences for patients and caregivers. These data may reflect hospitals/health professionals' lack of attention to older adults' functionality, focusing more on the treatment of acute diseases. In light of this, as a priority areas, health institutions and professionals should develop new knowledge, skills, and innovative approaches for promoting functionality during hospitalization.

\section{Acknowledgments}

We would like to thank the Nursing Board of the Coimbra Hospital and University Center, namely Nurse Director António Marques and Nurse Supervisor Eugénia Morais, for supporting the development of this study. 


\section{References}

Admi, H., Shadmi, E., Baruch, H., \& Zisberg, A. (2015). From research to reality: minimizing the effects of hospitalization on older adults. Rambam Maimonides Medical Journal, 6(2), e0017. doi.org/10.5041/ RMMJ.10201

Astiz, M., Sánchez García, E., Alonso Armesto, M., Montero Errasquin, B., Martínez de la Casa, A., Javier Ortiz, F., \& Antonio Serra Rexach, J. (2008). Deterioro funcional durante la hospitalización en ancianos. Beneficios del ingreso en el servicio de geriatría. Revista Española de Geriatría y Gerontología, 43(3), 133-138. doi.org/10.1016/S0211-139X(08)71172-7

Boltz, M., Lee, K. H., Chippendale, T., \& Trotta, R. L. (2018). Pre-admission functional decline in hospitalized persons with dementia: The influence of family caregiver factors. Archives of Gerontology and Geriatrics, 74, 49-54. doi.org/10.1016/J.ARCHGER.2017.09.006

Boyd, C. M., Landefeld, C. S., Counsell, S. R., Palmer, R. M., Fortinsky, R. H., Kresevic, D., ... Covinsky, K. E. (2008). Recovery of activities of daily living in older adults after hospitalization for acute medical illness. Journal of the American Geriatrics Society, 56(12), 2171-2179.

Conroy, S. P., Stevens, T., Parker, S. G., \& Gladman, J. R. F. (2011). A systematic review of comprehensive geriatric assessment to improve outcomes for frail older people being rapidly discharged from acute hospital: "Interface geriatrics." Age and Ageing, 40(4), 436-443. doi.org/10.1093/ageing/afr060

Covinsky, K. E., Pierluissi, E., \& Story, T. H. E. P. S. (2011). Hospitalization-Associated Disability "She Was Probably Able to Ambulate, but I'm Not Sure." Journal of the American Medical Association, 306(16), 1782-1793. doi.org/10.1001/jama.2011.1556

D’Onofrio, A., Bula, C., Rubli, E., Butrogno, F., \& Morin, D. (2018). Functional trajectories of older patients admitted to an Acute Care Unit for Elders. International Journal of Older People Nursing, 13(1), 13:e12164. http://doi.org/10.1111/opn.12164

Duque, S., Gruner, H., Clara, J., Ermida, J., \& Veríssimo, M. (n.d.). Avaliação Geriátrica. Núcleo de Estudos de Geriatria da Sociedade Portuguesa de Medicina Interna (GERMI). Retrieved from http://www.spmi.pt/docs_ nucleos/GERMI_36.pdf

Hoogerduijn, J. G., Schuurmans, M. J., Duijnstee, M. S. H., De Rooij, S. E., \& Grypdonck, M. F. H. (2007). A systematic review of predictors and screening instru- ments to identify older hospitalized patients at risk for functional decline. Journal of Clinical Nursing, 16(1), 46-57.

Huang, H. T., Chang, C. M., Liu, L. F., Lin, H. S., \& Chen, C. H. (2013). Trajectories and predictors of functional decline of hospitalised older patients. Journal of Clinical Nursing, 22(9-10), 1322-1331. doi. org/10.1111/jocn. 12055

Medina-Mirapeix, F., Bernabeu-Mora, R., García-Guillamón, G., Valera Novella, E., Gacto-Sánchez, M., \& García-Vidal, J. A. (2016). Patterns, Trajectories, and Predictors of Functional Decline after Hospitalization for Acute Exacerbations in Men with Moderate to Severe Chronic Obstructive Pulmonary Disease: A Longitudinal Study. PLOS ONE, 11(6), e0157377. doi. org/10.1371\%2Fjournal.pone.0157377

Palese, A., Gonella, S., Moreale, R., Guarnier, A., Barelli, P., Zambiasi, P., ... Saiani, L. (2016). Hospital-acquired functional decline in older patients cared for in acute medical wards and predictors: Findings from a multicentre longitudinal study. Geriatric Nursing, 37(3), 192-199. doi.org/10.1016/j.gerinurse.2016.01.001

Sleiman, I., Rozzini, R., Barbisoni, P., Morandi, A., Ricci, A., Giordano, A., \& Trabucchi, M. (2009). Functional Trajectories During Hospitalization: A Prognostic Sign for Elderly Patients. The Journals of Gerontology: Series A, 64A(6), 659-663.doi.org/10.1093/gerona/ glp015

Tavares, J., Grácio, J., \& Nunes, L. (2017a). Assessment of hospital environments and policies: seeking an age-friendly hospital. Revista Brasileira de Geriatria e Gerontologia, 20(2), 254-258. doi.org/10.1590/198122562017020.160095

Tavares, J., Grácio, J., \& Nunes, L. (2017b). Predictive validity of the Identification of Seniors at Risk - Hospitalized Patient tool for identifying functional decline. Revista de Enfermagem Referência, 4(15), 145-154. doi.org/10.12707/RIV17049

United Nations. (2015). World population ageing 2015. New York: United Nations.

Wakefield, B. J., \& Holman, J. E. (2007). Functional trajectories associated with hospitalization in older adults. Western Journal of Nursing Research, 29(2), 161-182. doi.org/10.1177/0193945906293809

Zisberg, A., Shadmi, E., Gur-Yaish, N., Tonkikh, O., \& Sinoff, G. (2015). Hospital-Associated Functional Decline: The Role of Hospitalization Processes Beyond Individual Risk Factors. Journal of the American Geriatrics Society, 63(1), 55-62. doi.org/10.1111/ jgs. 13193 